and $\mathrm{N}-4$ gave entirely satisfactory results in burning. Sample $\mathrm{N}-2$ was satisfactory but inferior to samples $\mathrm{N}-3$ and N-4. Sample N-r, the Natural Winter Oil, was fairly good as a burning oil.

Sample S-I represents an oil sample submitted by a fourth company. No information was furnished with this oil. The oil gave satisfactory results as a burning oil.

Sample F-4 represents an oil shipment which was entirely satisfactory. Samples $T-I$ and $T-2$ are from two different barrels of the shipment which caused considerable trouble. These oils encrusted the wicks very badly and were altogether unsatisfactory.

The nature of the adulteration in the unsatisfactory oils has not been determined. The table shows abnormal figures for refractive index (saponification value) and iodine value of the oil as well as for iodine values of fatty acids and alcohols, and for melting point of alcohols.

Results for the constants of the genuine sperm oils agree, in the main, with restults given in the literature. For some constants, the writers have found a somewhat wider variation than is generally noted in the technical literature (see Table II).

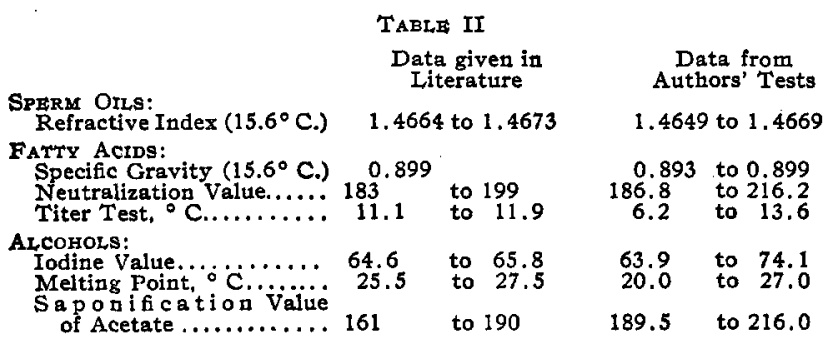

In connection with the writing of Specifications for Sperm Oil it has been the general custom to include requirements as to the maximum percentage of free acid allowed. In order to determine the effects of free acid upon the burning properties of sperm oil, experiments were made. with sperm oil to which had been added varying amounts of pure oleic acid. The oil was in each test burned in a Davy Miners' Safety Lamp. It was found that sperm oil containing $I, 2,3$ and up to 4 per cent added oleic acid caused a slight crust to form on the wick, but that oil with even 4 per cent oleic acid gave fairly satisfactory results. The addition of 5 per cent oleic acid caused heavier crust, while the addition of 6 per cent made the sperm oil entirely unsatisfactory for burning in a Davy Safety Lamp. It must be admitted that free acid has a harmful effect upon a burning oil, but it seems also that this effect has been somewhat overestimated in the case of sperm oil.

In judging the suitability of a sperm oil for burning purposes, one would do well to consider the iodine value and refractive index as well as the other constants and the free acid.

Some of the work above tabulated was done by $\mathrm{Mr}$. Donald Thorn, to whom the authors would acknowledge indebtedness.

Philadelphia \& Rqading Coal \& Iron Company Pottsville, PenNgyluania

\section{SOME EFFECTS OF CERTALN SOLVENTS ON TARS IN THE "FREE CARBON" DETERMINATION}

\author{
By G. S. MONROE AND H. J. BRODERSON
}

Received July 2, 1917

The work to be described was carried out in order to obtain some additional data which might throw some light on the probable condition of free carbon in tars, and the extent to which it or other substances in the tar might react with solvents used in the free carbon determination. There is much uncertainty as to the physical and chemical nature of free carbon as it exists in the original untreated tar. The fact that only part of the free carbon existing in tars, as shown by analysis, can be removed by filtration suggests the probability that it is present in a finely divided state. According to Abderhalden ${ }^{1}$ this free carbon exists in the tar as an emulsion, the emulsifying agent being the pitch oils present in the tar.

The first series of determinations was made to show the effect on the free carbon content of tars when the latter are allowed to stand in contact with the solvent at room temperature for different periods of time. The results showed a gradual increase in free carbon when benzene, bromobenzene, and chloroform were used. The numerical data are not given for this series of determinations as the results were of the same general nature as those recorded by Weiss. ${ }^{2}$

The next series of experiments was made to show the effect on the free carbon content of tars by digesting the tars with the solvent for different periods of time. In each determination $\mathrm{Io} \mathrm{g}$. of tar were added to Ioo cc. of solvent in an Erlenmeyer flask and digested on the water bath for a certain period of time, after which the tar solution was filtered through a weighed extraction thimble. This thimble was then placed in a Soxhlet extractor, extracted with the same solvent as that used in digestion, then dried and the insoluble residue weighed as free carbon. When chloroform was used as solvent, analyses were made for halogen in the free carbon residues by the peroxide method.3 These analyses were not made, however, in case of water-gas tar because the free carbon residues obtained were too small to work with conveniently. The results obtained by hot extraction are given in Table $I$.

\begin{tabular}{|c|c|c|c|c|}
\hline $\begin{array}{c}\text { TABI } \\
\text { MATERIAL } \\
\text { TREATED }\end{array}$ & $\begin{array}{l}\text { I-FREE CA } \\
\text { SOLVENT } \\
\text { USED }\end{array}$ & $\begin{array}{c}\text { BY HOT } \\
\text { Period } \\
\text { of } \\
\text { Digestion }\end{array}$ & $\begin{array}{c}\text { ExTRAction } \\
\text { Per cent } \\
\text { Free } \\
\text { Carbon }\end{array}$ & $\begin{array}{c}\text { Per cent } \mathrm{Cl} \\
\text { in Free Carbon } \\
\text { Residue }\end{array}$ \\
\hline Water-Gas Tar & Benzene & $\begin{array}{l}1 \text { hr. } \\
4 \text { hrs. } \\
7 \text { hrs. } \\
43 \text { hrs. }\end{array}$ & $\begin{array}{l}1.06 \\
1.33 \\
1.13 \\
1.17\end{array}$ & $\because:$ \\
\hline Gas-House Tar & Benzene & $\begin{array}{l}1 \text { hr. } \\
4 \text { hrs. } \\
40 \text { hrs. } \\
96 \text { hrs. }\end{array}$ & $\begin{array}{l}4.28 \\
4.47 \\
5.16 \\
4.68\end{array}$ & $\because$ \\
\hline Coke-Oven Tar & Benzene & $\begin{array}{l}1 \mathrm{hr} . \\
4 \mathrm{hrs.} \\
50 \mathrm{hrs.} \\
98 \mathrm{hrs.} \\
8 \text { days }\end{array}$ & $\begin{array}{r}6.13 \\
6.73 \\
9.33 \\
9.46 \\
11.83\end{array}$ & $\begin{array}{l}\because \\
\because \\
\therefore\end{array}$ \\
\hline Water-Gas Tar & Chloroform & $\begin{array}{l}1 \mathrm{hr} . \\
4 \mathrm{hrs.} \\
45 \mathrm{hrs.}\end{array}$ & $\begin{array}{l}0.77 \\
0.68 \\
0.97\end{array}$ & $\because$ \\
\hline Gas-House Tar & Chloroform & $\begin{array}{l}1 \text { hr. } \\
42 \text { hrs. } \\
3 \text { days }\end{array}$ & $\begin{array}{l}3.77 \\
4.63 \\
5.76\end{array}$ & $\begin{array}{l}0.55 \\
1.34 \\
2.64\end{array}$ \\
\hline
\end{tabular}

1 J. Gas Light., 123 (1913), 46-47.

2 ThIS JOURNAL, 6 (1914), 279-83.

J. F. Lemp. "A Method for the Determination of Halogens in Organic Compounds," Senior Thesis, University of Iulnois, 1917. 
The results given above show that in case of watergas tar and gas-house tar the free carbon percentages gradually approached a maximum value and then decreased when benzene was used as solvent. The same general behavior was observed in determination of free carbon in gas-house tar when toluene was used as solvent. In case of coke-oven tar, however, no maximum point was reached. This is due perhaps to the possibility that digestion was not continued long enough to reach the maximum point. It hardly seems wise to theorize as to the explanation of this maximum point until more data of this kind are available.

In the determination of free carbon made with chloroform as solvent no maximum value was observed, but the amount of free carbon gradually increased. This variation in free carbon which takes place when benzene, toluene, chloroform, etc., are used as solvents has been thought to be due to chemical reactions ${ }^{1}$ between the solvent and some of the tar constituents producing insoluble compounds which are continuously precipitated. That chemical reaction does take place in case of chloroform is shown conclusively by the fact, as observed by Weiss, that small crystals of amber

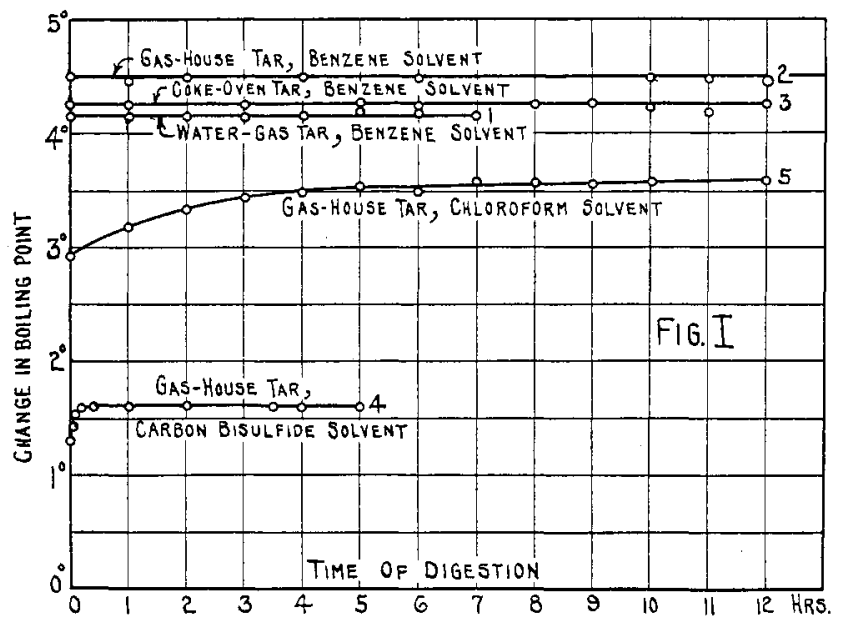

color were found throughout the free carbon residue when gas-house tar was digested with this solvent for three days. The amount, however, of this substance was too small to account for the observed increase in weight. The probability of chemical reaction in the tar solution in case of chloroform is also indicated by the presence of chlorine in the free carbon residues from gas-house tar, although the same might be explained in part on the basis of adsorption of some of the solvent by the free carbon present in the tar. This is especially true when it is considered that there is no definite relation between the amount of chlorine found and the total amount of so-called free carbon.

If the theory of chemical reaction is to explain partly, if not completely, the variations observed in the free carbon content of tars by continued digestion, there should be a fluctuation in the boiling temperatures of such solutions on digestion due to the change in the chemical nature of the constituents in the tar solution. The following experiments were not designed to predict

1 Weiss, THus Journal, 6 (1914), 279-83. the nature of the chemical reactions, if such take place, but to show whether such chemical changes do occur. The experiments were performed in the following manner: In each case $5 \mathrm{~g}$. of tar diluted with $50 \mathrm{cc}$. of solvent were placed in a standard type of apparatus used in determining the molecular weights of compounds by the boiling point method. To prevent the escape of solvent the condenser attached to the inner tube was closed with a mercury seal. The boiling points of solutions of tars with different solvents were observed at different intervals with a Beckmann thermometer. The barometric pressure was observed at the different intervals but was not found to be great enough to make any appreciable difference in the boiling temperature. The actual boiling temperatures were not observed but simply the changes in such temperatures. The results are shown by the curves in Fig. I. The Curves I, 2, 3, representing the digestions of watergas tar, gas-house tar, and coke-oven tar, respectively, are horizontal and show no fluctuations, hence no appreciable chemical reaction takes place between the tars and benzene. The experiment using carbon bisulfide as solvent shows the same probability as mentioned in case of benzene (Curve 4 ). The rapid rise observed in the first portion of the curve is perhaps due to the possibility that temperature equilibrium was not reached between the tar solution and the surroundings.

In the case where chloroform was used as solvent the boiling point showed a continuous rise, thus showing that chemical reaction took place appreciably in the tar solution (Curve 5). Unfortunately, only one tar (gas-house tar) was investigated using chloroform as solvent, but it is reasonable to suppose that other tars would give similar results.

\section{CONCLUSIONS}

The results thus far obtained are not sufficient to warrant any general conclusion as to what happens between the tars or parts of the tar and the solvent but the following are some of the indications:

I-Variations in percentages of free carbon for different periods of digestion should not be entirely attributed to chemical reactions between tar and solvent, thereby producing insoluble material which is gradually precipitated. It may be that due to dilution some of the free carbon which may have been in the colloidal condition has been precipitated.

II-While it is very probable that chemical reactions take place between tar and chloroform when the latter is used in determining free carbon in tars, such reactions cannot account completely for the gradual increase in free carbon on continued digestion.

III-If the selection of a solvent which when added to tar will not give rise to chemical reactions is the proper criterion in devising a method for the determination of free carbon, benzene, toluene, and carbon bisulfide should be selected in preference to chloroform.

Chemical laboratory

UNIVERSITY OF ILIINOIS, URBANA 